\title{
FLEXIBILIDADE EM PROJETOS DE ARQUITETURA: CONTRIBUIÇÕES A PARTIR DE UMA REVISÃO SISTEMÁTICA DA LITERATURA
}

\section{FLEXIBILITY IN ARCHITECTURAL DESIGN: CONTRIBUTIONS INDICATED BY A SYSTEMATIC LITERATURE REVIEW}

\author{
Heliara Aparecida Costa 1 \\ Instituto de Arquitetura e Urbanismo da Universidade de São Paulo, São Carlos, SP, Brasil, heliara@usp.br \\ Louise Logsdon 2 \\ Instituto Federal de Educação, Ciência e Tecnologia de Mato Grosso, Cuiabá, MT, Brasil, louise.logsdon@cba.ifmt.edu.br
}

Márcio Minto Fabricio ${ }^{3}$

Instituto de Arquitetura e Urbanismo da Universidade de São Paulo, São Carlos, SP, Brasil, marcio@sc.usp.br

\section{Resumo}

A produção massificada de habitações de interesse social, utilizada como estratégia para reduzir o déficit habitacional brasileiro, ampliou a discussão sobre a adoção de requisitos que incrementam a qualidade dos projetos. Nesse sentido, o conceito de Flexibilidade tem sido tratado como um atributo para atendimento das necessidades dos seus usuários, em seus diversos agrupamentos familiares, ao longo do tempo de permanência na moradia. Diante desse contexto, o objetivo deste trabalho é realizar uma Revisão Sistemática da Literatura (RSL) sobre Flexibilidade. Para condução, definiu-se um protocolo de pesquisa e buscaram-se artigos publicados nos últimos dez anos, em periódicos indexados. Por meio do software StArt, os artigos foram selecionados e classificados em categorias distribuídas em três tópicos: área de estudo, enfoque teórico e método. Os resultados demostram que a maioria dos trabalhos se relaciona à área de estudo de projetos habitacionais e processo de projeto; tem enfoque teórico nas características que conferem flexibilidade ao projeto; e, baseiam-se em método de estudos empíricos. Além disso, os dados apontam que o tema tem pouco destaque e abrangência nos veículos indexados, e ainda carece de estudos sobre o seu próprio campo teórico e terminologia, visto que não há uma caracterização clara dos conceitos e de termos similares, como Adaptabilidade. Ressalta-se a relevância deste trabalho por traçar um panorama contemporâneo sobre as pesquisas publicadas e por oferecer um contexto que elucida o que ainda precisa ser pesquisado.

Palavras-chave: Flexibilidade. Adaptabilidade. Revisão Sistemática da Literatura. Qualidade espacial. Qualidade de projeto.

\begin{abstract}
The mass production of social housing, used as a strategy to reduce the Brazilian housing deficit, widened the discussion about the adoption of requirements that increase the quality of projects. In this sense, the concept of flexibility has been treated as an attribute to meet the needs of its users, in its diverse family groups, throughout the time of permanence in the dwelling. In this context, the objective of this work is to perform a Systematic Review of Literature (SLR) on flexibility. A research protocol was defined and articles published in the last ten years were searched in indexed journals. Through the StArt software, articles were selected and categorized into three categories: study's area, theoretical approach, and methods. The results show that most of the work is related to housing design and the design process; has a theoretical approach on the characteristics that give flexibility to the project, and are based on empirical studies methods. Besides, the data point out that the thematic has little prominence and coverage in indexed journals, and still lacks studies on its own theoretical field and taxonomy, since there isn't a precise characterization of concepts and similar terms such as Adaptability. The relevance of this work is highlighted by the fact that RSL is justified not only by outlining the published research but also by providing a context that elucidates what still needs to be researched.
\end{abstract}

Keywords: Flexibility. Functionality. Systematic Literature Revie. Spatial quality. Design's quality.

How to cite this article:

COSTA, Heliara Aparecida; LOGSDON, Louise; FABRICIO, Márcio Minto. Flexibilidade em projetos de arquitetura: contribuições a partir de uma revisão sistemática da literatura. PARC Pesquisa em Arquitetura e Construção, Campinas, SP, v. 8, n. 3, p. 144-160, set. 2017. ISSN 19806809. Disponível em: <https://periodicos.sbu.unicamp.br/ojs/index.php/parc/article/view/8650206>. Acesso em: 19 jan. 2018.

doi:http://dx.doi.org/10.20396/parc.v8i3.8650206 


\section{Introdução}

Flexibilidade de projeto em arquitetura tem sua definição associada à capacidade de adaptação do edifício à mudança, considerando projeto e tecnologia construtiva, como forma de atender às necessidades do usuário ao longo do seu ciclo de vida, com otimização dos recursos envolvidos (RABENECK; SHEPPARD; TOWN, 1974; GALFETTI, 1997; SCHNEIDER; TILL, 2005a, 2011; KRONENBURG, 2007).

A adoção de estratégias de Flexibilidade em projetos de arquitetura intensificou-se especialmente no período pósguerra na Europa, quando a grande demanda por habitação, em especial para a classe trabalhadora, levou os projetistas a buscarem soluções alternativas de moradia com produção em massa, incluindo aí aquelas com caraterísticas flexíveis. Nessa época, o conceito de Flexibilidade foi introduzido no debate da produção da habitação, como uma forma de compensar a quebra do equilíbrio existente entre o habitante e o seu habitat, tendo em vista o afastamento do morador do processo de concepção e construção da sua moradia (SCHNEIDER; TILL, 2007; PAIVA, 2002).

No Brasil, o conceito de Flexibilidade vem sendo retratado em estudos sobre espaços de habitações de interesse social (HIS), principalmente nos últimos 20 anos, a partir do Programa de Arrendamento Residencial (PAR), de 1999; e do Programa Minha Casa Minha Vida (PMCMV), de 2009. Lançados para reduzir o déficit de moradias para a população de baixa renda, esses programas possuem produção massificada, padronizada e com área reduzida. Diante desse contexto, Flexibilidade tem sido enfatizada como solução potencial para os problemas gerados pela produção em escala das habitações promovidas pelo governo, possibilitando a personalização na fase de uso pelos próprios usuários. De forma abrangente, os estudos brasileiros buscam ampliar o conhecimento do conceito entre projetistas e agentes envolvidos na promoção das HIS no país. Especificamente, procuram melhor compreensão do termo e seus correlatos, bem como estratégias de aplicação (BRANDÃO, 2002; 2006); identificar projetos e instrumentos operadores de Flexibilidade (JORGE, 2011), analisar e propor projetos que ampliem a Flexibilidade espacial (VILLA; BERTULUCI; OLIVEIRA， 2015; MARROQUIM; BARBIRATO, 2007), avaliar qualidade de projetos e requisitos dos usuários (LOGSDON, OLIVEIRA, 2013).

Estudos apontam, no entanto, que o conceito de Flexibilidade carece de elucidação para ampliar sua compreensão em projetos de arquitetura residencial. Os conflitos que direcionam a essa necessidade iniciam na própria definição do termo presente nas bases de referências internacionais, as principais fontes dos estudos brasileiros. Há uma superposição entre as palavras
Flexibilidade e Adaptabilidade, usadas ora como sinônimos, ora como distintas nas abordagens e visões dos autores (TILL; SCHNEIDER, 2005; ISMAIL; RAHIM, 2011).

Para Moffatt e Russel (2001), Adaptabilidade é a capacidade de os edifícios acomodarem mudanças. Flexibilidade aparece como uma estratégia de Adaptabilidade. É também o caso de Friedman (2002) e de Ismail e Rahim (2011), que comentam a falta de coerência na definição dos termos e optam pelo uso da Adaptabilidade como definição geral. Contrariamente, há estudos que consideram Flexibilidade com hierarquia mais alta, classificando Adaptabilidade como um dos tipos de estratégia para uma arquitetura flexível. No Brasil, estudos relevantes adotam essa vertente, como Brandão e Heineck (1997), Brandão (2002; 2011); Marroquim e Barbirato (2007).

Flexibilidade e Adaptabilidade ainda encontram paralelo em Open Building (OB), teoria desenvolvida por John Habraken, como alternativa à habitação produzida em massa e despersonalizada, na Holanda, nas décadas de 1960 e 1970. A teoria OB privilegia processos de projeto e de construção que visam facilitar futuras alterações pelo usuário, intitulando esse método de Teoria dos Suportes. A base do conceito está na construção em camadas, possibilitando a previsão de cenários futuros, permitido pelo suporte (estrutura e serviços) adotado (ABREU; HEITOR, 2007).

Há ainda uma série de estratégias ligadas aos termos Flexibilidade e Adaptabilidade, como: expansibilidade, evolutividade, mobilidade, elasticidade, diversidade, polivalência, neutralidade, entre outros, que contribuem a ampliar dúvidas e métodos nas pesquisas. No entanto, há pesquisas que classificam tais estratégias, de forma mais ou menos equivalente (ABREU; HEITOR, 2007; BRANDÃO, 2011).

Este artigo usará o termo Flexibilidade como conceito chave e Adaptabilidade como um dos tipos de Flexibilidade ou estratégia para alcançá-la. $\mathrm{O}$ mesmo vale para Open Building: o termo é entendido neste trabalho como uma das estratégias de Flexibilidade, por ser um processo de projeto e de construção que promove características flexíveis à construção.

Diante desse contexto, o objetivo deste trabalho é realizar uma Revisão Sistemática da Literatura (RSL) sobre Flexibilidade no projeto de arquitetura, a fim de conhecer as Áreas de Estudo, o Enfoque Teórico abordado e os Métodos de Pesquisa adotados. Para cumprir esse objetivo, foram levantados e classificados artigos publicados em periódicos indexados, nos últimos dez anos, buscando: (1) áreas de estudo de maior interesse de trabalhos recentes, bem como os campos que ainda 
precisam ser explorados; (2) enfoque teórico dos estudos contemporâneos, que ampliem o esclarecimento da terminologia e conceitos empregados, bem como estratégias, diretrizes e propriedades de aplicação de Flexibilidade; (3) métodos de pesquisa utilizados, elucidando os tipos de resultados alcançados.

Esta Revisão Sistemática justifica-se pela necessidade de traçar um panorama atualizado das pesquisas publicadas sobre o tema e de oferecer um contexto dos estudos ainda necessários.

\section{Método e ferramenta de pesquisa}

RSL é um tipo de pesquisa bibliográfica que utiliza métodos explícitos, contábeis e sistemáticos. Consiste em buscar, sobre determinado tema, o que é conhecido, como é conhecido, como isso varia entre os estudos e, da mesma forma, o que não foi estudado em pesquisas anteriores (GOUGH; OLIVER; THOMAS, 2012).

A importância da RSL se faz evidente por diversos fatores: (1) basear-se em pesquisas pontuais é arriscado, porque qualquer pesquisa individual pode ser falha ou ter uma relevância limitada; (2) uma revisão sistemática fornece um quadro mais forte e abrangente, baseado em muitos estudos ao invés de um único estudo; (3) a tarefa de se manter a par de todas as pesquisas anteriores geralmente é muito grande para um indivíduo; (4) os resultados de uma revisão sistemática fornecem um contexto para interpretar os resultados de um novo estudo primário; (5) realizar novos estudos primários sem se informar sobre pesquisas anteriores pode resultar em pesquisas desnecessárias, inapropriadas, irrelevantes ou antiéticas (GOUGH; OLIVER; THOMAS, 2012).

Realizar revisões sistemáticas da literatura envolve três atividades chave: identificar e descrever pesquisas anteriores (mapear a pesquisa); avaliar criticamente os resultados de forma sistemática; e reunir as descobertas em uma declaração coerente, conhecida como síntese. Esperase ainda que os métodos sejam todos explicados e justificados (GOUGH; OLIVER; THOMAS, 2012).

Algumas ferramentas auxiliam os pesquisadores no trabalho de fazer revisões sistemáticas, de forma a organizar e facilitar o processo. No grupo de softwares pesquisado na internet, foram encontrados: Cochrane Collaboration, Rayyan, Stata, Meta-Essentials. Além destes, há indicações no fórum do ResearchGate de uso do Mendeley e do Endnote. Alguns deles são pagos e voltados às áreas específicas, como o Cochrane, determinado para a área médica. No Brasil, existe o StArt (State of the Art through Systematic Review), um software exclusivamente voltado à revisão sistemática da literatura que foi desenvolvido pelo Laboratório de Pesquisa em Engenharia de Software da Universidade Federal de São Carlos (LaPES-UFSCar).

O software selecionado para a condução desta RSL foi o StArt, versão 3.0.3 beta, pelo fato de ser nacional, de uso livre, gratuito e por permitir trabalho colaborativo. Além disso, é uma forma de valorizar, promover e divulgar produtos do conhecimento científico das universidades brasileiras, como é o caso da UFSCar que, por meio do LaPES, mantém o StArt em um constante processo de revisão e aprimoramentos, atendendo às sugestões apontadas pelos seus usuários.

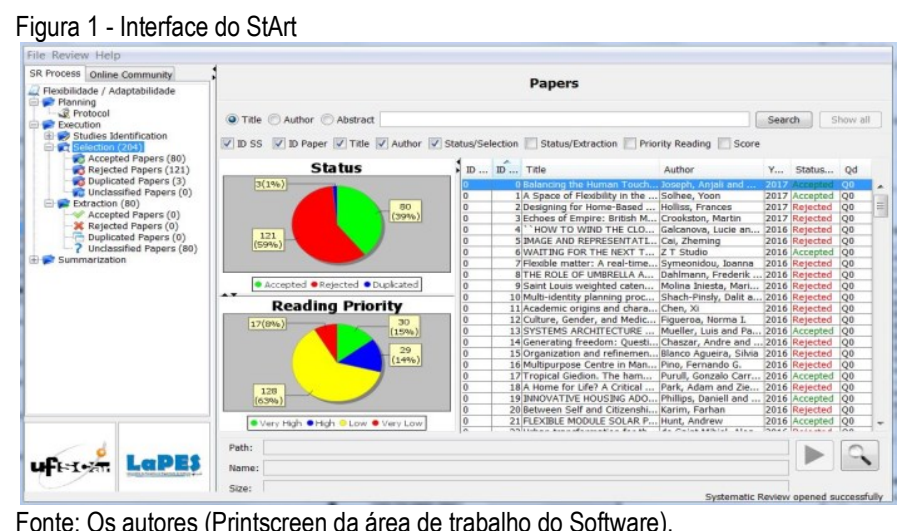

Por meio do StArt é possível estabelecer o protocolo de pesquisa; importar os dados dos artigos obtidos nas buscas realizadas nas bases de dados; fazer a primeira seleção dos artigos; fazer a classificação dos artigos lidos na íntegra e, por fim, visualizar gráficos gerados automaticamente com os resultados da revisão (FABBRI et al, 2016). A versão 3.0.3 beta do StArt permite trabalhar de forma colaborativa com outros pesquisadores em um mesmo arquivo de dados.

\section{Protocolo de pesquisa}

$\mathrm{O}$ primeiro passo da revisão sistemática foi definir o protocolo da pesquisa, dentro do StArt. No protocolo, identificaram-se os objetivos da revisão, as bases de dados que seriam utilizadas na busca dos artigos, os strings de busca (combinação de palavras-chave e filtros) e os critérios de seleção (inclusão e exclusão) e classificação dos artigos (Quadro 1).

\section{Condução das buscas dos artigos}

Após a elaboração do protocolo, realizaram-se as buscas nas bases de dados selecionadas: Web of Science, Scopus, Science Direct e Scielo, considerando a combinação de palavras-chave e os filtros indicados no Quadro 1. A definição das palavras-chave partiu de uma análise prévia, realizada pelos autores, de alguns artigos relevantes sobre o tema abordado, conforme sugerem Cooper, Hedges e Valentine (2009). Posteriormente, após a leitura de alguns resumos, os termos foram refinados. Foi utilizada a 
combinação "flexibility ou flexible ou adaptability ou adaptable", justamente pela superposição dos conceitos encontrados na literatura, como mencionado anteriormente. O termo Open Building não foi considerado na busca porque flexibility ou adaptability são, em regra, palavras associadas aos estudos abordados sobre o tema. Seguidamente, somou-se na busca a combinação "home design ou hous ${ }^{* 1}$ design ou space design", para que os artigos necessariamente tratassem de projetos de habitações ou espaços construídos, de uma maneira geral. Esta combinação foi necessária para eliminar os artigos da área da engenharia que tratam de assuntos muito diversos e que também adotam o termo Flexibilidade (como Flexibilidade em componentes elétricos, na arquitetura de softwares, em materiais diversos, no uso de equipamentos de automação, entre outros).

\begin{tabular}{|c|c|}
\hline $\begin{array}{l}\text { Campos do } \\
\text { protocolo }\end{array}$ & Conteúdo \\
\hline Pesquisadores & $\begin{array}{l}\text { Pesquisador } 1 \\
\text { Pesquisador } 2\end{array}$ \\
\hline Objetivo & $\begin{array}{l}\text { Levantar o estado da arte sobre Flexibilidade no } \\
\text { projeto arquitetônico, por meio do levantamento, } \\
\text { revisão e classificação de artigos publicados nos } \\
\text { últimos } 10 \text { anos em periódicos indexados. }\end{array}$ \\
\hline $\begin{array}{l}\text { Questões de } \\
\text { pesquisa }\end{array}$ & $\begin{array}{c}\text { Quais as Áreas de Estudo dos artigos publicados } \\
\text { dentro desta temática? } \\
\text { Qual o Enfoque Teórico abordado? } \\
\text { Quais os Métodos adotados? }\end{array}$ \\
\hline Bases de dados & $\begin{array}{c}\text { Web of Science } \\
\text { Scopus } \\
\text { Science Direct } \\
\text { Scielo }\end{array}$ \\
\hline Palavras-chave & $\begin{array}{c}\text { (Flexibility OR Flexible) OR (Adaptability OR } \\
\text { Adaptable) AND (Hous* design OR Home design OR } \\
\text { Space design). }\end{array}$ \\
\hline Filtros & $\begin{array}{c}\text { Ano de publicação: } 2007 \text { a } 2017 \\
\text { Tipo de publicação: Apenas artigos } \\
\text { Idioma: Inglês, Português e Espanhol } \\
\text { Área da pesquisa: Arquitetura, Engenharia, Ciências } \\
\text { Sociais, Ciências Ambientais, Artes e Humanidades. }\end{array}$ \\
\hline $\begin{array}{l}\text { Critérios de } \\
\text { seleção }\end{array}$ & $\begin{array}{l}\text { Inclusão: Trata de Flexibilidade no projeto de } \\
\text { arquitetura } \\
\text { Exclusão: Não trata de Flexibilidade; não é da área } \\
\text { da arquitetura / construção; não está nos idiomas } \\
\text { selecionados; o texto completo não foi encontrado. }\end{array}$ \\
\hline $\begin{array}{l}\text { Critérios de } \\
\text { classificação }\end{array}$ & ver quadro 2 \\
\hline
\end{tabular}

Fonte: Os autores

Os filtros foram aplicados de forma que as buscas resultassem em artigos publicados nos últimos 10 anos, nos idiomas de domínio dos autores (inglês, espanhol e português), e em áreas de conhecimento de arquitetura ou correlatas, como indicado no Quadro 1. Como resultado das buscas, obteve-se um total de 210 artigos: 160 no $\mathrm{Web}$ of Science; 39 no Scopus e 5 no Science Direct e 6 no Scielo. Em cada base de dados, as buscas foram salvas em formato ".bibtext" e importadas no StArt 3.0.3 para a etapa posterior, de seleção dos artigos.

\section{Seleção dos artigos}

Esta etapa foi integralmente realizada com uso do StArt 3.0.3. Por meio do software, criou-se um arquivo em que foram importadas as buscas em formato ".bibtext". Então $o$ arquivo do StArt foi dividido entre os pesquisadores, por meio do comando Review - Split Review. A seleção dos artigos se deu por meio da leitura do título, do abstract e das palavras-chave. Considerando os critérios de seleção (Quadro 1), os artigos foram aceitos ou rejeitados. O procedimento para executar revisões sistemáticas colaborativas no StArt está detalhadamente descrito no trabalho de Fabbri et al (2016).

Como resultado da fase de Seleção, 82 artigos foram aceitos para a etapa posterior. Foram descartados 128 artigos: 3 estavam duplicados e 125 foram rejeitados segundos os critérios de seleção. Dos artigos rejeitados, 29 não eram da área da arquitetura e os demais eram da área, mas não se referiam diretamente à Flexibilidade de projeto. É o caso, por exemplo, de um artigo que tratava dos contratos de prestação de serviços e ressaltava a importância da Flexibilidade dos mesmos.

\section{Extração ou classificação dos artigos}

Finalizada a etapa de seleção dos artigos, foi necessário buscar o texto completo dos artigos. O StArt não faz o link às bases de dados nem ao site dos periódicos. Sendo assim, os artigos selecionados foram obtidos de diferentes maneiras: (1) diretamente na base de dados; (2) acessando o periódico online onde o artigo foi publicado; (3) buscando o texto no Google Scholar; (4) solicitando o texto diretamente ao autor, pelo ResearchGate e (5) solicitando, na biblioteca da Instituição, uma cópia dos artigos a outras bibliotecas que possuíam a assinatura do periódico. Dos 84 artigos selecionados, apenas 7 não puderam ser acessados e, por isso, não foram classificados nesta pesquisa.

De posse dos textos completos, foi possível iniciar a etapa de extração propriamente dita: os artigos foram lidos na íntegra e classificados segundo os critérios estabelecidos, referentes a três tópicos: Áreas de Estudo, Enfoque Teórico e Método. Cada artigo deveria ser classificado de acordo com um ou mais critérios em cada tópico, como elencados no Quadro 2.

Importante ressaltar que 19 artigos foram rejeitados nesta etapa: por não estarem no idioma selecionado (2 artigos); porque não eram da área da arquitetura/construção (1 artigo); ou porque não tratavam de Flexibilidade de projeto, apesar de o abstract subentender desta forma (16 artigos). Sendo assim, excluindo os artigos que foram rejeitados (19), duplicados (2) ou que não puderam ser acessados (7), 54 trabalhos $(65,8 \%)$ foram classificados, dentro dos três grandes tópicos estabelecidos - enfoque, teoria e método da pesquisa. 


Quadro 2 - Critérios de classificação dos artigos
\begin{tabular}{|c|l|}
\hline Tópico & Critérios de Classificação \\
\hline & Processo de Projeto \\
& Habitação \\
1. Áreas de & Edifícios comerciais \\
Estudo & Edifícios Institucionais \\
& Arquitetura vernacular \\
& Equipamentos urbanos \\
& Tecnologia das construções \\
\hline & Aborda o conceito de Flexibilidade \\
& Aborda o conceito de Adaptabilidade \\
& Aborda o conceito de Open Building, \\
& Define os tipos de Flexibilidade ou Adaptabilidade \\
2. Enfoque & Discute vantagens e desvantagens do uso da \\
Teórico & flexibilidade \\
& Diretrizes para elaboração de projetos flexíveis \\
& Aborda características que conferem Flexibilidade ao \\
& projeto \\
\hline 3. Método de & Artigo não científico \\
Revisão da literatura & Estudo empírico \\
& Proposição do artefato (DSR) \\
\hline
\end{tabular}

Fonte: Os autores

O capítulo seguinte apresenta o resultado da classificação dos artigos, tomando como referência para a tabulação de dados a estrutura de apresentação de Wang et al. (2013).

\section{Resultados}

\section{Classificação dos artigos por ano de publicação}

O número de artigos por ano de publicação é mostrado no Gráfico 1. Nota-se que a maior parte das publicações datam de 2007 (12 artigos), 2011 (10 artigos) e 2015 (10 artigos). Apenas um artigo foi publicado em 2009 e, no ano de 2017, nenhum artigo. Não há uma tendência clara de crescimento ou queda linear no número de publicações dos últimos dez anos, mas é possível dizer que o tema permanece em discussão ao longo do período, com alguns picos de maior ou menor publicação.

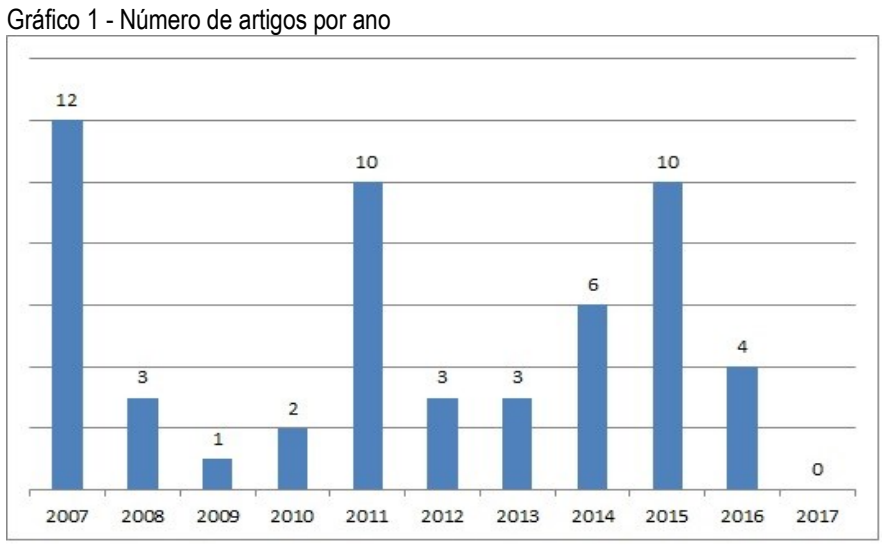

Fonte: Os autores

\section{Classificação dos artigos por periódico}

Os artigos selecionados para a classificação foram publicados em 21 periódicos distintos. No entanto, 38,8\% deles (21 artigos) encontram-se na Open House International (OHI), o que demonstra a relevância deste na divulgação de pesquisas acerca da Flexibilidade.

A OHI foi iniciada na Holanda, em 1976, por Nicholas Wilkinson, membro da Fundação de Pesquisa de Arquitetos (Stichting Architecten Research - SAR). A SAR foi fundada por N. J. Habraken, um dos grandes pesquisadores sobre Flexibilidade no ambiente construído. O periódico tem hoje cerca de 400 assinantes e publica trimestralmente em março, junho, setembro e dezembro (WILKINSON, 2017). A revista foi classificada como A2 na área de Arquitetura, Urbanismo e Design (AU+ D), no período de 2010 a 2012 (Qualis CAPES). Atualmente (período 2013 a 2016), a publicação não está listada na área de $\mathrm{AU}+\mathrm{D}$, e comparece na área de Engenharias I, na categoria B2 do Qualis CAPES .

Em segundo lugar, em número de artigos publicados, está o Journal of Asian Architecture and Building Engineering, que contém 5 dos 54 artigos encontrados. Em terceiro lugar, está a revista ARQ, com 4 artigos. Dentre os 21 periódicos encontrados, 14 deles possuem apenas uma publicação relacionada a esta pesquisa. A Tabela 1 elenca os periódicos e o número de publicações encontradas em cada um deles:

Tabela 1 - Número de artigos por periódico

\begin{tabular}{|c|c|}
\hline Periódico & $\begin{array}{l}\mathrm{N} . \mathrm{de} \\
\text { artigos }\end{array}$ \\
\hline Open House International & 21 \\
\hline Journal of Asian Architecture and Building Engineering & 5 \\
\hline$A R Q$ & 4 \\
\hline Architectural Design & 3 \\
\hline Archnet-IJAR & 3 \\
\hline International Journal of Applied Engineering Research & 2 \\
\hline Ambiente Construído & 2 \\
\hline Arquitecturas Del Sur & 1 \\
\hline Journal of Green Building & 1 \\
\hline Frontiers of Architecture Research & 1 \\
\hline Megaron & 1 \\
\hline Journal of Landscape Architecture & 1 \\
\hline Arquitetura Revista & 1 \\
\hline Open Construction and Building Technology Journal & 1 \\
\hline A/Z ITU Journal of the Faculty of Architecture & 1 \\
\hline International Journal for Housing Science and Its Applications & 1 \\
\hline WIT Transactions on Ecology and the Environment & 1 \\
\hline Smart and Sustainable Built Environment & 1 \\
\hline Libri & 1 \\
\hline Habitat International & 1 \\
\hline Kybernetes & 1 \\
\hline
\end{tabular}

Importante ressaltar que o idioma de veiculação da grande maioria dos artigos (46 artigos - 85\%) era o inglês. Dos demais, 5 estavam escritos em espanhol (Periódicos $A R Q$, Arquitectura del Sur e Arquitectura Revista), dois em 
português, e um deles estava em espanhol e inglês (Periódico ARQ).

\section{Classificação dos artigos segundo as Áreas de Estudo}

A Tabela 2 mostra a quantidade de artigos publicados, segundo as Áreas de Estudo, nas seguintes categorias: processo de projeto; habitação; edifícios comerciais; edifícios institucionais; arquitetura vernacular; equipamentos urbanos e tecnologia das construções. Inicialmente, era intenção dos autores a busca por artigos sobre habitação. No entanto, optou-se em ampliar a busca para quaisquer tipologias construtivas, por dois motivos: primeiro, para verificar a área de maior interesse, dentre os estudos sobre Flexibilidade; segundo, porque as estratégias de Flexibilidade adotadas em edifícios comerciais ou institucionais, por exemplo, podem ser válidas também para edifícios habitacionais.

Sendo assim, a classificação dos artigos encontrados segundo as categorias de enfoque pretende mostrar qual o foco dos estudos em Flexibilidade, nos últimos dez anos, identificando padrões e tendências de pesquisas.

Tabela 2 - Número e porcentagem de artigos, segundo as Áreas de Estudo

\begin{tabular}{lcc}
\hline Tópico 1: Enfoque & N. de Artigos & Porcentagem \% \\
\hline 1. Processo de Projeto & 12 & $22,22 \%$ \\
2. Habitação & 34 & $62,96 \%$ \\
3. Edifícios comerciais & 5 & $9,26 \%$ \\
4. Edifícios Institucionais & 7 & $12,96 \%$ \\
5. Arquitetura vernacular & 4 & $7,41 \%$ \\
6. Equipamentos urbanos & 2 & $3,70 \%$ \\
7. Tecnologia das Construções & 4 & $7,41 \%$ \\
\hline
\end{tabular}

Fonte: Os autores

Atenta-se ao fato de que um mesmo artigo pode se relacionar a uma, duas ou mais Áreas de Estudo - por exemplo, tratar do tema habitação e também processo de projeto. Por isso, a soma da coluna N. de Artigos na Tabela 2 não é 54 (total de artigos). No entanto, a coluna Porcentagem \% indica o percentual de documentos dentro de uma categoria de área (Número de artigos da categoria dividido por 54).

Na Tabela 2, nota-se que a maior parte dos estudos em Flexibilidade aborda o projeto de habitação $(62,96 \%)$. Isso não é surpresa, visto que a Flexibilidade é colocada por vários autores como um princípio que confere qualidade ao projeto de unidades habitacionais, em especial às de interesse social, no sentido de que um projeto flexível se adequa melhor a uma diversa gama de usuários, cujas necessidades podem variar muito conforme o tempo de permanência na moradia.

Em segundo lugar estão os artigos que relacionam a Flexibilidade ao processo de projeto. Doze artigos $(22,22 \%)$ possuem este enfoque. Em ordem decrescente, a sequência segue com o foco em edifícios institucionais (7 artigos - 12,96\%); edifícios comerciais (5 artigos $9,26 \%$ ); arquitetura vernacular (4 artigos, 7,41\%); tecnologia da construção (4 artigos - 7,41\%) e equipamentos urbanos (2 artigos - 3,70\%).

Pode-se dizer, portanto, que nos últimos dez anos, as Áreas de Estudos com maior enfoque sobre Flexibilidade esteve nos projetos habitacionais e em processo de projeto, de uma maneira geral. A maior carência está na tecnologia da construção, em que apenas 4 artigos focam em sistemas construtivos e processos de construção flexíveis. Da mesma forma, equipamentos urbanos têm recebido pouca atenção por parte dos pesquisadores.

A relação entre as Áreas de Estudo e a frequência de publicação no período pesquisado (Gráfico 2), demonstram que:

1. A quantidade de artigos relacionados a processo de projeto aumentou nos últimos 4 anos;

2. O número de artigos relacionados à habitação foi quase sempre superior aos relacionados às outras categorias, com exceção em 2010, quando a Área de Estudo de maior enfoque foi edifícios institucionais. $\mathrm{O}$ ano que mais teve publicações nesta categoria foi em 2015;

3. A maioria dos artigos relacionados a edifícios comerciais datam de 2007 (4 artigos), sendo que houve uma única outra publicação em 2015;

4. Os artigos relacionados à tecnologia da construção datam de 2011, 2012 e 2013.

5. Os artigos relacionados a equipamentos urbanos são recentes, datam de 2014 e 2015.

A tabela 3 elenca a referência dos artigos classificados em cada categoria do Tópico 2 - Enfoque Teórico.

\section{Classificação dos artigos segundo o Enfoque Teórico}

Um dos objetivos desta revisão sistemática era observar o Enfoque Teórico abordado pelos trabalhos, agrupando-os segundos suas semelhanças. Dessa forma, os artigos foram classificados em sete categorias: (1) Aborda o conceito de Flexibilidade, (2) Aborda o conceito de Adaptabilidade, (3) Aborda o conceito de Open Building, (4) Define os tipos de Flexibilidade ou Adaptabilidade, (5) Discute vantagens e desvantagens do uso da flexibilidade, (6) Apresenta diretrizes para elaboração de projetos flexíveis, (7) Aborda características que conferem Flexibilidade ao projeto. A tabela 3 mostra a quantidade de artigos publicados em cada uma das categorias citadas. 
Gráfico 2 - Número de artigos por ano, segundo a Áreas de Estudo

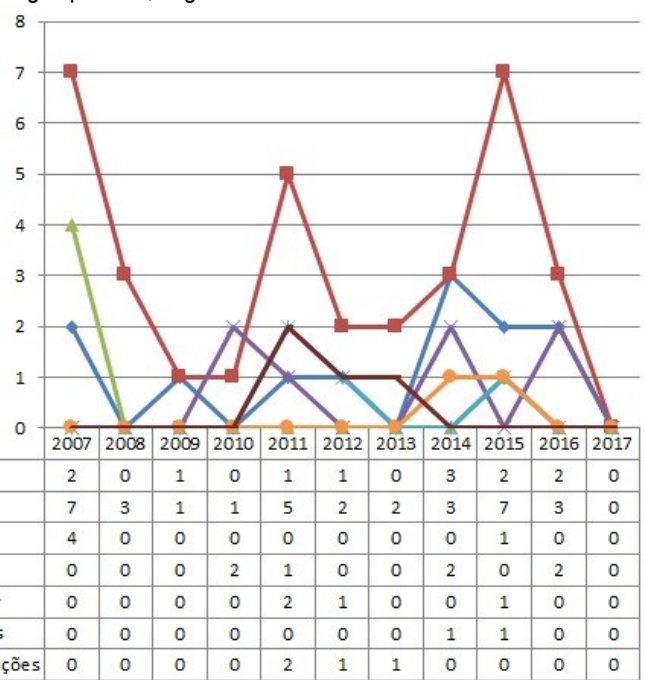

Fonte: Os autores

Da mesma forma como ocorreu no item anterior, um mesmo artigo pode abordar mais de uma categoria definida no Tópico 2 - Enfoque Teórico. Dessa maneira, a soma da coluna número de artigos na Tabela 3 não é 54 (total de artigos), mas a coluna Porcentagem \% indica o porcentual de documentos dentro de uma determinada categoria (número de artigos da categoria / 54).

Tabela 3 - Número e porcentagem de artigos, segundo o Enfoque Teórico

\begin{tabular}{lrr}
\hline Tópico 2: Enfoque Teórico & $\begin{array}{c}\text { Número } \\
\text { de artigos }\end{array}$ & $\begin{array}{c}\text { Porcentagem } \\
\%\end{array}$ \\
\hline 1. Aborda o conceito de Flexibilidade & 36 & $66,67 \%$ \\
2. Aborda o conceito de Adaptabilidade & 19 & $35,19 \%$ \\
3. Aborda o conceito de Open Building & 13 & $24,07 \%$ \\
$\begin{array}{l}\text { 4. Define os tipos de Flexibilidade ou } \\
\text { Adaptabilidade }\end{array}$ & 4 & $7,41 \%$ \\
$\begin{array}{l}\text { 5. Discute vantagens e desvantagens do uso } \\
\text { da flexibilidade }\end{array}$ & 2 & $3,70 \%$ \\
$\begin{array}{l}\text { 6. Diretrizes para elaboração de projetos } \\
\text { flexíveis }\end{array}$ & 11 & $20,37 \%$ \\
7. Aborda características que conferem & & \\
Flexibilidade ao projeto & 42 & $77,78 \%$ \\
\hline Fonte: Os autores & & \\
\hline
\end{tabular}

Analisando os dados da Tabela 3, nota-se que a maior parte dos estudos aborda características que conferem Flexibilidade ao projeto (42 artigos - 77,78\%). São artigos que analisam projetos de edifícios, ressaltando as características que os fazem flexíveis. Muitas vezes, estes artigos não trazem definição de conceitos e, em alguns casos, a Flexibilidade não é o foco principal da análise. É o caso, por exemplo, do artigo de Tomita e Ishii (44), que trata dos efeitos psicológicos de Hannes Meyer na arquitetura soviética da década de 1930 . O enfoque não é Flexibilidade, mas o trabalho demonstra como o projeto da Brigada de Bauhaus era flexível, com espaços que podiam ser tecnologicamente expansíveis para acomodar grandes apresentações de massa.
Com relação aos conceitos adotados, 36 artigos abordam o conceito de Flexibilidade, 19 abordam o conceito de Adaptabilidade e 12 referem-se ao conceito de Open Building. O termo Flexibilidade predomina, mas muitas vezes, é tratado em conjunto com um dos outros dois.

Apenas quatro artigos elencam os tipos de Flexibilidade ou Adaptabilidade e apenas dois discutem as vantagens e desvantagens da aplicação da Flexibilidade. Por fim, um número razoável de artigos (20,37\%) traz diretrizes para a elaboração de projetos flexíveis.

A frequência de publicação em relação ao Enfoque Teórico (Gráfico 3) dos estudos realizados no período de 2007-2017 direcionam às seguintes observações:

1. A quantidade de artigos que apresentam características que conferem Flexibilidade ao projeto é sempre superior que as demais, com exceção no ano de 2012, quando não há nenhum artigo classificado nesta categoria;

2. A quantidade de artigos que abordam o conceito de Flexibilidade é sempre superior que os que abordam os conceitos de Adaptabilidade ou Open Building;

3. Apenas no ano de 2011 a quantidade de artigos que abordam o conceito de Open Building é maior que os que abordam o conceito de Adaptabilidade;

4. Os artigos que tratam dos tipos de Flexibilidade são recentes, datam de 2010; 2014 e 2015;

5. Os artigos que discutem vantagens e desvantagens do emprego da Flexibilidade no projeto datam de $2011 \mathrm{e}$ 2016.

Para melhor apresentar os resultados encontrados, a fim de facilitar a tabulação e análise dos dados, a Quadro 3 elenca a Referência dos Artigos que foram classificados em cada categoria de teoria.

\section{Classificação dos artigos segundo o Método}

A terceira e última categoria de classificação dos artigos buscou analisar qual o método empregado nas pesquisas selecionadas. Quatro categorias foram criadas inicialmente: (1) artigo não científico - para publicações em revistas de arquitetura que apenas apresentam uma análise formal de projetos de edifícios; (2) revisão da literatura - quando o artigo tem base apenas em revisão/ fundamentação teórica; (3) estudo empírico - quando o artigo apresenta dados provenientes de estudos de casos, avaliações pós-ocupação, entrevistas, grupos focais, etc; (4) Proposição de artefato - quando o artigo é resultado de uma Design Science Research e traz como resultado algum artefato relacionado à Flexibilidade de projetos. 
Gráfico 3 - Número de artigos por ano, segundo o Enfoque Teórico.

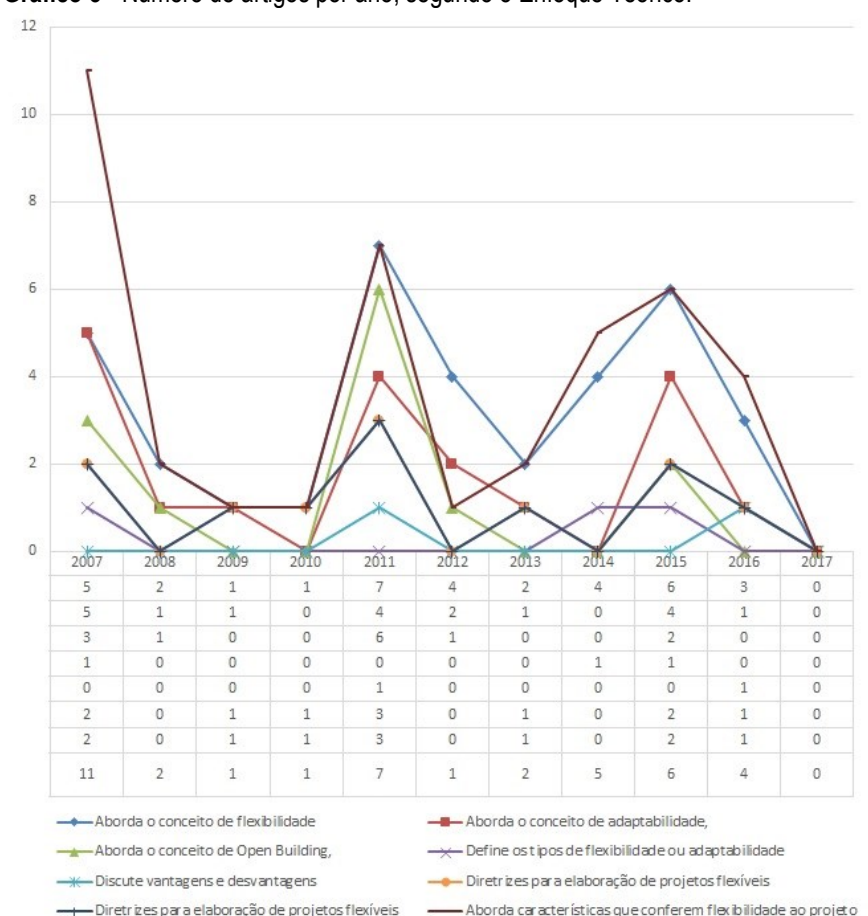

Fonte: Os autores

Quadro 3 - Referência dos artigos, segundo as categorias de Enfoque Teórico

\begin{tabular}{|c|c|}
\hline Tópico 2: Teoria & Referência dos artigos \\
\hline $\begin{array}{l}\text { 1. Aborda o conceito } \\
\text { de Flexibilidade }\end{array}$ & $\begin{array}{l}\text { (11); (12); (2); (3); (50); (4); (16); (17); (19); (48); } \\
(20) ;(5) ;(\text { (51); ( }(52) ;(6) ;(22) ;(24) ;(25) ;(27) ;(28) ; \\
\text { (29); (8); (30); (31); (32); (33); (34); (35); (36); (49); } \\
\text { (37); (38); (39); (53); (54). }\end{array}$ \\
\hline $\begin{array}{l}\text { 2. Aborda o conceito } \\
\text { de Adaptabilidade, }\end{array}$ & $\begin{array}{l}\text { (2); ; (15); (19); (20); (5); (6); (24); (25); (27); (28); } \\
\text { (29); (8); (30); (33); (36); (49); (37); (39); (53), (54). }\end{array}$ \\
\hline $\begin{array}{l}\text { 3. Aborda o conceito } \\
\text { de Open Building, }\end{array}$ & $\begin{array}{c}\text { (2); (18); (48); (20); (5); (51); (52); (24); (26); (29); } \\
\text { (31); (49); (54). }\end{array}$ \\
\hline $\begin{array}{l}\text { 4. Define os tipos de } \\
\text { Flexibilidade ou } \\
\text { Adaptabilidade }\end{array}$ & (4); (33); (5); (54). \\
\hline $\begin{array}{l}\text { 5. Discute vantagens e } \\
\text { desvantagens do uso } \\
\text { da flexibilidade }\end{array}$ & (11); (5). \\
\hline $\begin{array}{l}\text { 6. Diretrizes para } \\
\text { elaboração de projetos } \\
\text { flexíveis } \\
\end{array}$ & $\begin{array}{c}\text { (19); (21); (6); (29); (8); (30); (32); (36); (37); (38); } \\
\text { (39); (54). }\end{array}$ \\
\hline $\begin{array}{l}\text { 7. Aborda } \\
\text { características que } \\
\text { conferem Flexibilidade } \\
\text { ao projeto }\end{array}$ & $\begin{array}{l}\text { (1); (5); (6); (7); (8); (9); (10); (11); (12); (13); (14); } \\
\text { (15); (16); (17); (18); (19); (20); (22); (23); (24); } \\
\text { (25); (26); (27); (28); (29); (30); (32); (33); (34); } \\
\text { (35); (36); (37); (39); (40); (41); (42); (43); (44); } \\
\text { (45); (46); (48); (49); (51); (53). }\end{array}$ \\
\hline
\end{tabular}

Fonte: Os autores.

Como ilustra a Tabela 4, a maior parte dos artigos $(79,63 \%)$ consiste em estudos empíricos. Geralmente, são análises de projetos de edifícios segundo determinados critérios, dentre eles a Flexibilidade.

Em segundo lugar, 20 artigos $(37,04 \%)$ trazem uma revisão da literatura consistente que aborda a teoria acerca da Flexibilidade. Seis artigos apresentam uma estrutura não científica, publicados em revistas de arquitetura que têm foco em apenas apresentar uma edificação e sua autoria.

Por fim, cabe ressaltar que nenhum dos artigos utilizou o método de Design Science Research, com proposição de artefatos, o que, inicialmente, era algo de interesse dos autores.

Tabela 4 - Número e porcentagem de artigos, segundo o Método

\begin{tabular}{lcc}
\hline \multicolumn{1}{c}{ Tópico 3: Métodos } & $\begin{array}{c}\text { Número de } \\
\text { artigos }\end{array}$ & $\begin{array}{c}\text { Porcentagem } \\
\%\end{array}$ \\
\hline 1. Artigo não científico & 6 & $11,11 \%$ \\
2. Revisão da literatura & 20 & $37,04 \%$ \\
3. Estudo empírico & 43 & $79,63 \%$ \\
4. Proposição de artefato (DSR) & 0 & $0,00 \%$ \\
\hline Fonte: Os autores & &
\end{tabular}

O Gráfico 3 apresenta a distribuição das publicações ao longo dos anos, também de acordo com o Método da Pesquisa.

Pela análise do Gráfico, observa-se que a quantidade de estudos empíricos é sempre maior que a de artigos com revisão da literatura. Isso porque boa parte dos trabalhos que apresenta estudos empíricos traz também alguma revisão da literatura.

Em contrapartida, muitos artigos apresentam apenas uma descrição da edificação (seu contexto social, necessidades dos usuários, técnicas construtivas, características do projeto, entre outros), sem demonstrar uma revisão consistente sobre o tema Flexibilidade, com definição do conceito, estratégias e sua importância. No ano de 2015, uma grande quantidade de estudos empíricos foi publicada, somando dez artigos somente neste ano.

Gráfico 3 - Número de artigos por ano, segundo as categorias de Método

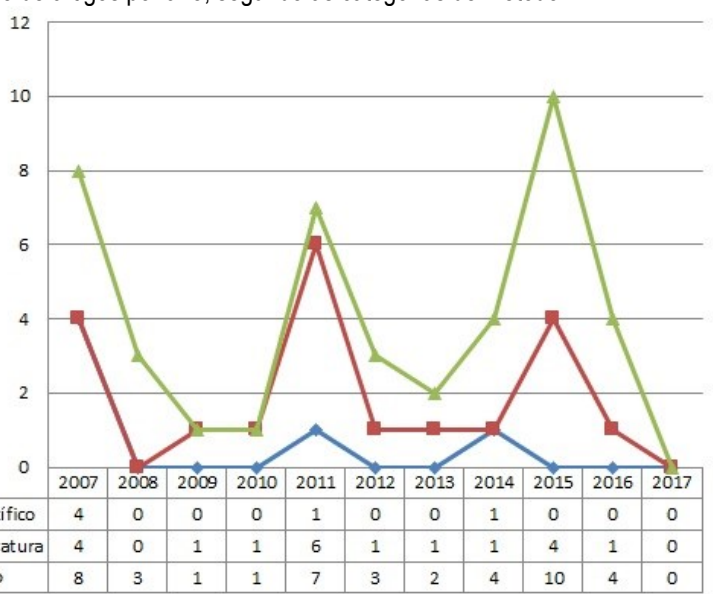

Fonte: Os autores

Por fim, a quantidade de artigos não científicos é bem pequena, se comparados às demais categorias, e todos eles 
datam de 2011 ou 2014. São artigos publicados em revistas de arquitetura, cujo objetivo é apresentar uma análise formal e funcional de projetos arquitetônicos, geralmente recém-construídos e/ou projetados.

Para facilitar a leitura, o Quadro 4 elenca a referência dos artigos que foram classificados nas categorias estabelecidas para o Tópico 3 - Método.

Quadro 4 - Referência dos artigos, segundo as categorias de Método:

\begin{tabular}{|c|c|}
\hline Tópico 3: Métodos & Referência dos artigos \\
\hline 1. Artigo não-científico & (4); (45); (40); (7); (41); (42). \\
\hline 2. Revisão da literatura & $\begin{array}{c}\text { (11); (14); (19); (48); (20); (5); (21); (6); (27); } \\
\text { (28); (43); (29); (30); (33); (34); (36); (37); (47); } \\
\text { (53). }\end{array}$ \\
\hline 3. Estudo empírico & $\begin{array}{l}\text { (1); (2); (3); (8); (9); (10); (11); (12); (13); (14); } \\
\text { (15); (16); (17); (18); (19); (21); (22); (23); (24); } \\
\text { (26); (27); (28); (29); (30); (31); (33); (34); (35); } \\
\text { (36); (37); (38); (39); (42); (44); (46); (47); (48); } \\
\text { (49); (51); (53); (54). }\end{array}$ \\
\hline
\end{tabular}

Fonte: Os autores, 2017.

\section{Discussão dos Resultados}

Este estudo de Revisão Sistemática da literatura analisou 54 artigos sobre o tema Flexibilidade na arquitetura, indexados em periódicos no período de 2007 a 2017. Os resultados apresentados, de acordo com protocolo estabelecido, direcionam a discussão das seguintes questões:

- Flexibilidade é um tema de frequência relativamente baixa na maior parte dos periódicos. Nos últimos dez anos, o tema possui publicação em fluxo constante, mas relativamente baixo, com picos em intervalos de quatro anos;

- Habitação é a tipologia arquitetônica que recebe maior número de contribuição nos estudos sobre Flexibilidade. Nota-se que a aplicação do conceito é variada, de acordo com país de origem. Apesar de um número pequeno de artigos, espaço urbano é tratado como objeto passível de aplicação de estratégias flexíveis;

- Processo de projeto é a área de estudo de maior interesse sobre o tema; de maneira oposta, tecnologias construtivas promotoras de Flexibilidade é área pouco abordada;

- Como já mencionado, flexibilidade é um campo que necessita de estudos sobre conceitos e taxonomia, o que se reafirmou diante das diferentes abordagens e nomes utilizados nos artigos revisados.

Os resultados demonstram que Flexibilidade possui baixa frequência de publicação na maior parte dos periódicos internacionais. Dos 21 periódicos que constam na pesquisa, 14 apresentam a publicação de um artigo (por periódico) na última década. Por outro lado, apenas um dos periódicos foi responsável pela publicação de um total 21 artigos. Não por coincidência, este veículo é o Open House Internacional (OHI), cuja fundação está relacionada à promoção das ideias do grupo $\mathrm{SAR}$, fundado por Habraken, conforme já comentado.

Este fato mostra que, apesar do SAR ter encerrado suas atividades em 1999, supostamente por acreditar que suas ideias básicas, no contexto holandês, tinham sido suficientemente assimiladas (ABREU E HEITOR, 2007), a revista relacionada a grupo - $\mathrm{OHI}$ - continua sendo o veículo que mais publica estudos na área. Isso mostra que o tema foi entendido, mas não esgotado. As ideias básicas estão definidas, assimiladas, mas o tema continua relevante, visto que as pesquisas atuais, em sua grande parte $(80,77 \%)$, estão focadas em estudos de caso e no desenvolvimento de aplicações ou soluções do conceito de flexibilidade para o processo de projeto.

Com relação aos estudos que tratam sobre habitação tema de maior interesse entre os artigos analisados parece haver uma inter-relação sobre $\mathrm{o}$ grau de desenvolvimento econômico dos países e a maneira como a Flexibilidade é empregada. Em países de maior desenvolvimento, grande parte dos artigos sobre Flexibilidade habitacional aborda a capacidade de adaptação da moradia às necessidades de uma mesma família ao longo do tempo, com ou sem alteração da área construída; ou a capacidade da habitação se ajustar ao perfil de várias famílias, nos casos de mudança de endereço, aumentando desta forma a vida útil e reduzindo custos com reformas. Artigos com esse enfoque aparecem no Canadá (artigo 6), Austrália (11), Estados Unidos (13), Espanha (32) e Itália (35). Estes tratam o tema Flexibilidade para habitação de interesse social, com soluções para otimizar recursos, custos e promover a sustentabilidade ambiental, além de ampliar a qualidade pelo atendimento às necessidades dos usuários e às suas dinâmicas de vida.

Um dos melhores exemplos é do Canadá (6). A pesquisa apresenta um estudo de caso da comunidade de Widow's Row, na cidade de Iqaluit. A partir da necessidade de reformar habitações de um bairro de interesse social, os autores adotaram conceitos de Flexibilidade, tanto no plano urbano, quanto no plano das unidades residenciais, tendo como base um estudo social, demográfico, econômico, cultural, climático e um survey com moradores. No plano urbano, o acesso de veículos e a relação destes com pedestres foram analisados, bem como as formas de socialização entre as pessoas. De igual forma, as unidades habitacionais foram planejadas para atender aos requisitos dos moradores, incluindo aspectos práticos e culturais, com espaços suficientes para a família e 
possíveis acréscimos para abrigar novos membros por meio de ambientes multi-uso. Os autores afirmam que a Flexibilidade por si só não resolverá todos os problemas da habitação pública no ártico canadense, mas potencializa uma melhor adequação ambiental, econômica e cultural para as moradias na região.

Artigos provenientes de países em desenvolvimento como Botswana (8) e Brasil (10) (54) - aplicam Flexibilidade com estratégias Evolutiva ou Ampliável, que facilitam ampliação da área construída, conforme classificação demonstrada nos estudos de Brandão (2006, 2011) e Paiva (2002). Nessa perspectiva, percebe-se uma distinção sobre o uso do conceito na arquitetura brasileira, o que pode ser justificado em função da política habitacional adotada no país ao longo de anos.

Estudos apontam que as moradias sociais produzidas nos últimos vinte anos - PAR e PMCMV - possuem espaços reduzidos e localização urbana periférica, como forma de baratear o produto e aumentar o lucro das construtoras (CARDOSO; ARAGÃO; ARAUJO, 2011). Em grande parte, as casas são térreas e isoladas, com a sugestão do uso de Flexibilidade planejada para ser Ampliável ou Evolutiva, conforme indicado no manual de "Conceitos Orientadores para Concepção de Projetos para HIS" da Caixa Econômica Federal (2015): "compreende os aspectos relacionados às possibilidades de expansão (vertical ou horizontal) da unidade habitacional e à diversidade de arranjos de implantação". No entanto, o banco de projetos da Caixa traz exemplos não flexíveis. Fica a cargo do usuário a tarefa de aumentar o espaço de sua residência e garantir por si próprio a qualidade habitacional.

No texto sobre Flexibilidade na comunidade de Botswana (8), a abordagem flexível buscou "maximizar o potencial de adições futuras diante das necessidades econômicas e sociais dos habitantes". No Brasil, (10), estudo para a comunidade "Céu do Terceiro Mundo", o autor afirma que no projeto de uma das habitações "os quartos da casa estavam ligados a este corredor grande e alto com independência suficiente para permitir que crescessem". Esses dois projetos foram realizados por autoconstrução e seus méritos são reconhecidos, igualmente o uso da Flexibilidade Evolutiva. Apenas usa-se como exemplo para demonstrar as diferentes aplicações do conceito entre os países.

Essa análise leva à hipótese de que nos países desenvolvidos Flexibilidade é um tema que interessa como solução arquitetônica, atendendo aos requisitos de qualidade habitacional para população consumidora de habitação.

Com relação aos estudos que tratam do processo de projeto (10 artigos), alguns padrões puderam ser notados. Dois deles trazem uma abordagem mais teórica: um ressalta a importância do conceito de polivalência no processo de projeto (4), e o outro discute a possibilidade de investigar a Flexibilidade de edifícios por meio dos algoritmos evolucionários caracterizados por Darwin, ilustrando como os princípios evolutivos (variação, seleção e replicação) poderiam ser aplicados à arquitetura (5). Estes estudos, em especial, não apresentam estudos empíricos ou proposições.

Em contrapartida, sete artigos são estudos empíricos: por meio de estudos de casos, fazem considerações acerca do processo de projeto.

- O artigo (1) e (2) referem-se a concursos de arquitetura, destacando as recomendações que os projetos deveriam seguir - dentre eles, a Flexibilidade (em um dos casos, aparece o conceito de arquitetura de sistemas e, no outro, o conceito de modelo não linear) - e os processos dos projetos vencedores.

- Os artigos (3) e (7) analisam as obras e as intenções projetuais dos arquitetos de algumas obras selecionadas. O artigo (3) refere-se a seis projetos residenciais do Irã, demonstrando as estratégias de Flexibilidade adotadas em função da estrutura, do layout e da organização dos espaços de serviços. O artigo (7) comenta quatro projetos espanhóis que ilustram o uso de Flexibilidade e sua tendência racionalista, característica do discurso espanhol nos anos 1960.

- Os artigos (6), (10) e (8) descrevem o processo de projeto empregado em casos onde se buscava uma arquitetura flexível. O artigo (6) traz o caso de um projeto de HIS realizado pelos próprios autores, que esclarecem como os princípios de Flexibilidade foram incorporados no processo. $\mathrm{O}$ artigo (10) apresenta o caso onde foi adotado um processo de projeto flexível, não linear, indeterminado, e com participação do usuário. Na mesma linha, o artigo (8) propõe como alternativa à produção habitacional de Botswana um processo de projeto não linear, sistemático e interativo, a fim de melhorar a qualidade das moradias oferecidas à população de baixa renda.

Ainda sobre a área de estudo processo de projeto, apenas um artigo tem uma abordagem mais propositiva, apresentando um modelo para a participação do usuário na customização em massa de habitação (9). Essa análise mostra a baixa quantidade de artigos que, de fato, apresentam ferramentas ou proposições práticas para auxiliar o processo de projeto na aplicação do conceito de Flexibilidade. Não foram encontrados artigos que tratassem de BIM (Building Information Modelling), por exemplo, e nenhum artigo utilizava métodos científicos mais propositivos, como a Design Science Research. 
No campo teórico, notifica-se a ausência de uma unidade nos conceitos usados nos artigos. Das 52 revisões, apenas 13 apresentam o conceito de Flexibilidade, Adaptabilidade e Open Building (artigos 6, 8, 11, 15, 20, 24, 27, 18, 32, $33,36,48,49)$. Maior parte dos artigos cita Flexibilidade usando o significado generalizado da palavra, com ideias relativas à capacidade de transformação sem, no entanto, dar uma definição de acordo com o escopo teórico da arquitetura. Os textos que buscam esse conteúdo dão ênfase na distinção entre Flexibilidade e Adaptabilidade, principalmente (artigo, 6, 8, 15, 11, 24, 32, 33, 36). Porém, não há um consenso no uso da terminologia. Alguns autores comentam que o uso indistinto dos dois termos (artigo $8,15,33$ ) é suscetível a interpretações variadas e concordam que o campo necessita de um trabalho ampliado sobre a taxonomia e conceitos. A definição mais citada é a de Schneider e Till (2005, p. 157), que conceitua Flexibilidade como o tipo de "habitação projetada para permitir escolhas ainda no processo de projeto, em termos de uso e construção, ao longo do ciclo de vida”. Em uma definição ampliada, estes autores descrevem que $o$ conceito "inclui a opção de layouts variados no período pré-ocupação e a capacidade de ajustes na pós-ocupação. Essas alterações podem ser em decorrência de novas tecnologias, ajustes demográficos, ou mudança total da função do edifício" (TILL; SCHNEIDER, 2005, p. 287).

Esses autores são sem dúvida os mais referenciados nos artigos revisados em que o conceito é, ao menos, abordado $(6,8,11,24,32$ e 33). Nos textos originais, Schneider e Till (2005b) e Till e Schneider (2005) declaram preferir o uso de Flexibilidade e a consideraram como categoria mais ampla que Adaptabilidade (adaptable house), colocada como "termo geralmente adotado para denotar habitação que pode se adaptar às necessidades físicas dos usuários, em particular à medida que envelhecem ou perdem a mobilidade" (TILL; SCHNEIDER, 2005). Embora de forma reducionista, essa definição se aproxima do que afirma Friedman (2002), que usa o termo Adaptabilidade como principal. Apesar de afirmar que uma das justificativas para uma habitação ser adaptável esteja relacionada às questões de saúde ou envelhecimento, levando a necessidade de transformações dos espaços como a instalação de um homecare, por exemplo Friedman define Adaptabilidade como a maneira de prover ocupantes com formas e meios que facilitem o ajuste entre as necessidades de espaço e as limitações de suas casas, antes ou depois da ocupação. (FRIEDMAN, 2002)

Nessa vertente, a revisão identificou também artigos que apresentam o conceito de Adaptabilidade (artigos 6, 8, 15 e 24). Beisi (1995), artigo (6), define Adaptabilidade como "forma de atender à diversidade de necessidades dos usuários e proprietários e suas alterações por meio dos potenciais permitidos pelos sistemas técnicos e de gestão de uma edificação". Na tentativa de pontuar a diferença, Groak (2002), artigo (6), insere Flexibilidade como um processo de projeto que permite diferentes arranjos; já, Adaptabilidade como a habitação que pode se adaptar a diferentes funções/usos (8). Parte desta definição também aparece na definição de Üstün (2000), artigo (15): "Flexibilidade como um método que depende dos princípios de construção e distribuição de espaços de serviço [...] dependente das relações planejadas entre os eixos estruturais e divisões internas, sistema de aquecimento central, instalação de água, de eletricidade e áreas de serviço", entendidas aqui como lavanderia, banheiro. Por outro lado, "Adaptabilidade é baseada em planejamento e organização [...]" com o objetivo de "proporcionar oportunidade de reutilização do espaço residencial $[. .$.$] ". Neste artigo também está presente o$ conceito de Tapan (1972), que expõe Flexibilidade como a "capacidade de uma mesma unidade cumprir requisitos de diferentes usuários sem alterar o sistema estrutural". No artigo (24), Adaptabilidade é classificada como um tipo de estratégia que permite a Flexibilidade. Percebe-se que a diferença entre os termos Flexibilidade e Adaptabilidade assume versões variadas, gerando dúvidas que levam ao uso indistinto pelos pesquisadores.

Sobre a teoria de Open Building, esta também é referenciada (artigos 8, 15, 20, 24, 30, 36). OB é conceituada de acordo com o que preconizou J.N. Habraken em sua obra "Supports: an alternative to mass housing" (1961-1972), em que defende a participação do usuário no projeto da moradia, possibilitada pelo suporte (ou elementos estruturais) e pelo recheio (infill). Mas, OB não escapa do caldeirão de definições diversificadas. $O$ artigo (24) apresenta OB como estratégia de Flexibilidade. E o artigo (38) coloca os dois conceitos como sinônimos.

Para além de Flexibilidade, Adaptabilidade e Open Building, no decorrer da revisão foram anotados outros termos que surgiram com significados similares. $\mathrm{O}$ artigo (15) apresenta "Variabilidade" como expansão externa da edificação por um sistema de módulos. A Teoria "Dynamic Dwelling" (24) é citada como a que deu origem à Habitação Flexível, com crédito a Herbert (1978). De acordo com o autor, esta teoria diz respeito à capacidade de resposta congruente das configurações físicas da habitação ao comportamento humano, em circunstâncias variáveis, no tempo de vida útil da edificação. No artigo (30), afirma-se que Flexibilidade também significa "Modificabilidade", citando Saari (2008) e Kendal (2000). Ainda é apresentado o termo "Flexi-living" (36), como conceito atribuído a Mcburnie (2006), que se aplica à diversidade do ambiente urbano, compreendendo misto de lotes, habitações e rede de diferentes vias. Polivalência (36) tem origem em Hertzberger (1991). Originalmente, o autor afirma que "Flexibilidade representa o conjunto de todas as soluções inadequadas para um problema". 
Holandês e contemporâneo de Habraken, Hertzberger atua de forma crítica às habitações construídas sob o desígnio da Flexibilidade. Sua proposta é que os edifícios se adaptem à diversidade, mas sem fugir de sua identidade. Para ele, Flexibilidade pode se adaptar a qualquer solução proveniente de necessidades de mudança, mas nunca será a melhor ou a mais adequada. Entende-se que essa crítica está relacionada à Flexibilidade de função, em que são previstas alterações de edifícios comerciais em residenciais ou em outro tipo, mas que são construídos com "identidade" formal semelhante.

Nos artigos que não retratam diretamente sobre Flexibilidade, Adaptabilidade e Open Building, também surgiram termos como Arquitetura de Sistemas (1), MultiPurpose Design (48) e Espaço Indeterminado (10).

Observa-se que Flexibilidade é assunto pouco publicado no contexto contemporâneo estrangeiro. Apesar de alguns autores considerarem a hipótese de o conceito ter sido suficientemente assimilado, como no caso do grupo SAR e do movimento Open Building na Holanda, o campo teórico ainda necessita de definições mais precisas, como uma padronização internacional dos conceitos e termos adotados. Essa sistematização pode favorecer maior divulgação e confiança por parte de pesquisadores e profissionais projetistas na adoção de Flexibilidade, como forma de ampliar a qualidade do espaço edificado, principalmente de HIS, no contexto de países em desenvolvimento. Porém, necessário reiterar que Flexibilidade esteja integrada à adoção de políticas públicas que privilegiam também espaços urbanos adequados às necessidades da população.

\section{Conclusão}

Os resultados e sua discussão levam à conclusão de que Flexibilidade ainda carece de consenso sobre o seu próprio campo teórico, a fim de caracterizar melhor conceitos e terminologias, como Adaptabilidade, Open Building e outros coletados no decorrer deste estudo.

Evidenciou-se que há uma estreita ligação entre arquitetura flexível e projeto habitacional, com maior ênfase no processo de projeto; e menor em tecnologia. Indica a necessidade de estudos mais completos, que integrem processos, materiais, tecnologias e técnicas. Há um campo aberto para exploração de pesquisas com artefatos ou proposições.

Tanto quanto o projeto habitacional, o projeto urbano, também é passível de aplicação do conceito, a exemplo do artigo (6), em que a qualidade da habitação relaciona-se diretamente a qualidade do espaço público.

Outra importante contribuição desta Revisão Sistemática é a constatação da aplicação do conceito relacionado à política habitacional. Conjecturou-se que, em países com economia mais desenvolvida, a Flexibilidade é adotada como estratégia para ampliar a qualidade e a vida útil das edificações. É recomendado que as futuras pesquisas sobre o tema tragam proposições projetuais e soluções tecnológicas que contribuam com a melhoria da qualidade dos projetos da habitação, incluindo o espaço urbano..

\section{Agradecimentos}

Ao Laboratório de Pesquisa em Engenharia de Software da Universidade Federal de São Carlos (LaPES-UFSCar), pelo apoio oferecido aos autores na utilização do StArt, versão 3.0.3 beta, essencial para o desenvolvimento deste trabalho.

Ao CNPq (Conselho Nacional de Desenvolvimento Científico e Tecnológico), pela bolsa produtividade em pesquisa (Processo No 306185/2015-6).

Ao Instituto Federal de Educação, Ciência e Tecnologia de Mato Grosso (IFMT. Campus Cuiabá), pelo afastamento concedido à autora Louise Logsdon, para realizar o doutorado no Instituto de Arquitetura e Urbanismo da Universidade de São Paulo (IAU-USP).

Ao Instituto de Arquitetura e Urbanismo (IAU), da Universidade de São Paulo (USP), pela estrutura de pesquisa.

\section{Notas}

(1) O asterisco utilizado no termo hous*, para as buscas nas bases de dados, serve para agregar quaisquer palavras que iniciem com hous: house, houses, housing, etc. 


\section{Referências}

ABREU, R.; HEITOR, T. Estratégias de Flexibilidade na arquitetura doméstica holandesa: da conversão à multifuncionalidade. Infohabitar - Revista Semanal sobre o Habitat Humano, Lisboa, n. 122, jan., online, jan. 2007. Disponível em: < http://infohabitar.blogspot.com.br/2007/01/estratgias-de-flexibilidade-na.html >. Acesso em: 10/7/2017.

BRANDÃO, D. Q. Diversidade e potencial de Flexibilidade de arranjos espaciais de apartamentos: uma análise do produto imobiliário brasileiro. 2002. 443 f. Tese (Doutorado em Engenharia de Produção) - Universidade Federal de Santa Catarina, Florianópolis.

Disposições técnicas e diretrizes para projeto de habitações sociais evolutivas. Ambiente Construído (Online), Porto Alegre, v. 11, n. 2, p. 73-96, June 2011. doi: http://dx.doi.org/10.1590/S1678-86212011000200006.

Habitação social evolutiva: aspectos construtivos, diretrizes para projetos e proposição de arranjos espaciais flexíveis. Cuiabá: CEFETMT, 2006.

BRANDÃO, D. Q.; HEINECK, L. F. M. Formas de aplicação da Flexibilidade arquitetônica em projetos de edifícios residenciais multifamiliares. In: ENCONTRO NACIONAL DE ENGENHARIA DE PRODUÇÃO. Anais... Gramado: ABEPRO, PPGEP/UFSC, 1997.

CARDOSO, A. L.; ARAGÃO, T. A.; ARAUJO, F. D. S. Habitação de interesse social: política ou mercado? Reflexos sobre a produção do espaço metropolitano. In: ENCONTRO NACIONAL DA ANPUR, 14., 2011, Rio de Janeiro. Anais... Rio de Janeiro: ANPUR, maio de 2011. Disponível em: <papers3://publication/uuid/AE17045C-60F0-45FA-8D31-F3F4812355D5>. Acesso em: 15 de julho de 2017.

COOPER, H.; HEDGES, L.V.; VALENTINE, J.C. Handbook of Research Synthesis and Meta-Analysis, Second Edition. New York: Russell Sage Foundation, 2009.

DHAR, T.K.et al. How does flexible design promote resource efficiency for housing? A study of Khulna, Bangladesh. Smart and Sustainable Built Environment, v. 2, n. 2, p. 140-157, 2013. https://doi.org/10.1108/SASBE-10-2012-0051

FABBRI, S. et al. Improvements in the StArt tool to better support the systematic review process. In: INTERNATIONAL CONFERENCE ON EVALUATION AND ASSESSMENT IN SOFTWARE ENGINEERING. 21, 2016, Limerick. Proceedings... Limerick: ACM/Digital Library, 2016. doi: http://dx.doi.org/10.1145/2915970.2916013

FRIEDMAN, A. The Adaptable House. Designing Homes for Change. New York: McGraw-Hil, 2002.

GALFETTI, G. G. Model apartments: experimental domestic cells. Barcelona: Gustavo Gili, 1997.

GOUGH, D, OLIVER, S, THOMAS, J. An introduction to systematic reviews. London: Sage Publications Ltd,, 2012.

ISMAIL, Zulkefle; ABDUL RAHIM, Asiah. Adaptibility and modularity in housing: a case study of Raines Court and Next21. In: INTERNATIONAL CONFERENCE ON UNIVERSAL DESIGN IN BUILT ENVIRONMENT, 2011, Kuala Lumpur.

Proceeding... Kuala Lumpur: KAED Universal Design Unit, nov. 2011. Disponível em: < http://irep.iium.edu.my/12603/>. Acesso em: 13 de junho de 2017

JORGE, L. O. Estratégia de Flexibilidade na arquitetura residencial multifamiliar. Tese (Doutorado em Arquitetura) Programa de Pós Graduação em Arquitetura e Urbanismo, Universidade de São Paulo, São Paulo, 2012,511 f.

KRONENBURG, R. Flexible. Architecture that responds to change. London: Laurence King, 2007.

LOGSDON, L; OLIVEIRA, R. O Programa Minha Casa Minha Vida em Cuiabá-MT-Brasil: uma análise da qualidade dos projetos destinados às famílias de baixa renda. In: CONGRESSO INTERNACIONAL DA HABITAÇÃO NO ESPAÇO LUSÓFONO, 2,13 a 15 de março de 2013, Lisboa. Anais... Lisboa: LNEC, 2013.

MOFFATT, S.; RUSSEL, P. Assessing the adaptability of buildings. In: ANNEX 31 Background Reports - Energy-related environmental impact of buildings. Otawa: iiSBE, 2001. Disponível em: $<$ http://www.ieaebc.org/Data/publications/EBC_Annex_31_Assessing_Building.pdf >. Acesso em: 15 de maio de 2017. 
RABENECK, A. SHEPPARD, D.; TOWN, P. Housing flexibility/adaptability? Architectural Design, London, v. 49, p. 76-91, fev. 1974.

SCHNEIDER, T; TILL, J. Flexible Housing: opportunities and limits. Arq: Architectural Research Quaterly, Sheffield, vol 9. n 2. p. 157-166, junho 2005. doi: https://doi.org/10.1017/S1359135505000199

Flexible Housing. Oxford: Architectural Press, 2007.

TILL, J.; SCHNEIDER, T. Flexible Housing: the means to the end. arq: Architectural Research Quarterly, v. 9, n. 3/4, p. 287296, 2005. https://doi.org/10.1017/S1359135505000345

VILLA, S.B; BERTULUCI, G.O.; OLIVEIRA, J. C. C.B. Estratégias de adensamento horizontal e vertical e sustentabilidade para habitação social: experiência do Projeto Mora. In: II CONGRESSO INTERNACIONAL DE HABITAÇÃO COLETIVA SUSTENTÁVEL, 2016, São Paulo. Anais... São Paulo: Master Laboratório de la Vivienda Sostenible del Siglo XXI / FAUUSP, 2016. v. 1. p. $370-375$.

WANG, X. et al. Augmented Reality in built environment: Classification and implications for future research. Automation in Construction, v. 32, n. April 2016, p. 1-13, 2013. https://doi.org/10.1016/j.autcon.2012.11.021

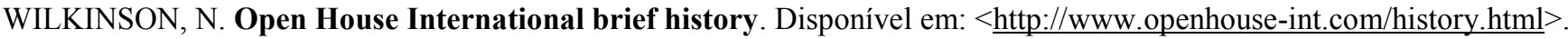
Acesso em 10 agosto de 2017.

\section{Bibliografia [artigos classificados pela RSL]}

1. MÜLLER, L.; PARERA, C. Arquitectura de sistemas y programas sociales en la Argentina desarrollista: del optimismo a lo possible. Arquitecturas del Sur, Chile, v. 34, n. 49, p. 32-41, 2016.

2. STOJANOVIC, D.; STAMENOVIC, P. Non-linear model in architectural design for sustainable social housing: case study Ovca Housing Project Belgrade. Open House International, v. 40, n. 4, p. 30-43, 2015.

3. FARJAMI, G. Authentic emergence of flexibility in contemporary architecture. Open House International, v. 40, n. 4, p. 4449, 2015.

4. HERTZBERGER, H. Polyvalence: The Competence of Form and Space with Regard to Different Interpretations. Architectural Design, v. 84, n. 5, p. 106-113, 2014

5. SCHWEHR, P. Evolutionary Algorithms in architecture. Open House International, v. 36, n. 1, p. $289-299,2011$.

6. DEBICKA, E.; FRIEDMAN, A. Flexible design of public housing in Iqaluit Nunavut, Canada. Open House International, v. 34, n. 4, p. 26-35, 2009.

7. MONTANER, J.M. Selected Spanish Projects. Architectural Design, v. 77, n. 5, p. 102-109, 2007. http://dx.doi.org/10.10.1002/ad.524

8. JOBE, K.; WILliAMS, C.J.K. Flexible Design and Construction Strategies for Self-Help Housing in Botswana. Open Construction and Building Technology Journal, v. 10, n. 3, p. 381-394, 2016. doi: http://dx.doi.org/10.2174/1874836801610010381

9. DINÇER, A.E.; TONG, H.; et al. A computational model for mass customized housing design bu using cellular automata. A/Z ITU Journal of the Faculty of Architecture, v. 11, n. 2, p. 351-368, 2014.

10. CABRAL FILHO, J.D.S.C. An indeterminate project for architecture in Brazil. Kybernetes, v. 36, n. 9/10, p. 1266-1276, 2007. doi: http://dx.doi.org/10.1108/03684920710827283

11. PHILLIPS, D.; GUARALDA, M. Innovative housing adoption: Modular housing for the Australian growing family. Journal of Green, U.S.A., p. 147-170, 2016. doi: http://dx.doi.org/10.3992/jgb.11.2.147.1

12. KIM, M.K.; KIM, M.J. Affordable modular housing for college students emphasizing habitability. Journal of Asian Architecture and Building Engineering, v. 15, n. 1, p. 49-56, 2016. doi: http://dx.doi.org/10.3130/jaabe.15.49 
13. CINN, E.; Song, H. An architect's adaptation to the mass production pystem: A Quincy Jones' s Tract Houses. Journal of Asian Architecture and Building Engineering, v. 14, n. 3, p. 561-568, 2015. doi: http://dx.doi.org/ 10.3130/jaabe.14.561

14. RASHID, M.; ARA, D.R. Modernity in tradition: Reflections on building design and technology in the Asian vernacular. Frontiers of Architectural Research, v. 4, n. 1, p. 46-55, 2015. doi: http://dx.doi.org/10.1016/j.foar.2014.11.001

15. HIZLI, N. Re-Thinking Loft Buildings in the Scope of Housing Production in Turkey*. MEGARON / Yıldız Technical University, Faculty of Architecture E-Journal, v. 10, n. 4, p. 479-493, 2016. doi: http://dx.doi.org/10.5505/MEGARON.2015.04127

16. CESARIS, A. De; MANDOLEZI, D. Modular, sustainable and customized: project for the contemporary dwelling. Open House International, v. 38, n. 3, p. 39-47, 2013.

17. KAHN, T.H.; DHAR, T.K. Flexibility in Hong Kong private housing. Open House International, v. 37, n. 3, p. 48-59, 2012.

18. SAIGO, T.; SAWADA, S.; et al. Future direction of sustainable buildings in Japan. Open House International, v. 36, n. 4, p. $5-19,2011$

19. BEISI, J.; YINGYING, J. Flexibility of traditional buildings and craftsmanship in China. Open House International, v. 36, n. 4, p. 20-31, 2011.

20. BEISI, J.; YINGYING, J. The Tendency of the "Open Building” Concept in the Post- Industrial Context. Open House International, v. 36, n. 1, p. 325-335, 2011.

21. LAU, W.K.; HO, D.C.W. Open Building Implementation in high-rise residential buildings in Hong Kong. Open house international, v. 36, n. 1, p. 25-34, 2011.

22. CONENNA, C. Un manifiesto velado de la modernidad: Casa Palicka (1929-1932), Praga Mart Stam - Jirí Palicka. Arquitetura Revista, Rio Grande do Sul, v. 4, n. 2, p. 45-51, 2008. doi: http://dx.doi.org/10.4013/arq.20082.05

23. AUBREY, D. Response to rapid change: post-tsunami shelter in Sri Lanka. Open House International, v. 33, n. 2, p. 32-39, 2008.

24. KARNI, E. Openings in façades and adaptable dwelling space. Open House International, v. 33, n. 1, p. 37-45, 2008.

25. MINAMI, K. A post-occupancy evaluation of layout changes made to KEP adaptable housing. Journal of Asian Architecture and Building Engineering, v. 6, n. 2, p. 245-250, 2007. doi: http://dx.doi.org/10.3130/jaabe.6.245

26. BEISI, J. Residential designs from Baumschlager \& Eberle - An evaluation. Open House International, v. 32, n. 3, p. 7-15, 2007.

27. AKALIN, A.; YILDIRIM, K.; et al. User interventions in turkish mass housing. Open House International, v. 32, n. 3, p. 77-89, 2017.

28. PARK, J.-H. A Highrise Urban Village: tectonic Mutation in a design studio. Open House International, v. 32, n. 1, p. 3040, 2007.

29. YILDIZ, D. Evaluating Change in housing for sustainable development: Kosuyolu Case in Istanbul. Open House International, v. 40, n. 4, 2015.

30. ALARAJI, K.A.M.H.; JUSAN, M.B.M. Flexible house attributes as perceived by the end-users. International Journal of Applied Engineering Research, v. 10, n. 7, p. 18313-18324, 2015.

31. JINXIU, W.; MEIYING, Z.; et al. Study on high comfort and low energy consumption community design in China. Open House International, v. 40, n. 2, p. 1-12, 2015.

32. MONTELLANO, A.S. Housing flexibility by spatial indeterminacy: The case of the Casa de las Flores in Madrid. International Journal of Architectural Research - Archnet-IJAR, v. 9, n. 2, p. 4-19, 2015. 
33. RAVIZ, S.R.H.; ETEGHAD, A.N.; et al. Flexible Housing: the Role of Spatial Organization in Achieving Functional Efficiency. International Journal of Architectural Research: ArchNet-IJAR, v. 9, n. 2, p. 65-76, 2015. doi: http://dx.doi.org/10.26687/archnet-ijar.v9i2.422

34. ALARAJI, K.; JUSAN, M.M. Assessment of perceived flexibility in house design using conjoint analysis (CA). International Journal of Applied Engineering Research, v. 9, n. 14, p. 2473-2486, 2014.

35. BOLOGNESI, C.; MAZZOLENI, P. 125 Cases os new social design houses compared. Int. Journal for Housing Science, v. 38, n. 4, p. 251-260, 2014.

36. DHAR, T.K.; HOSSAIN, M.; et al. How does flexible design promote resource efficiency for housing? A study of Khulna, Bangladesh. Smart and Sustainable Built Environment, v. 2, n. 2, p. 140-157, 2013. doi: http://dx.doi.org/10.1108/SASBE10-2012-0051

37. GELIL, N.A. Less Space, More Spatiality for Low Income Housing Units in Egypt: Ideas from Japan. International Journal of Architectural Research - Archnet- IJAR, v. 5, n. 2, p. 24-48, 1994. doi: http://dx.doi.org/10.26687/archnet-ijar.v5i2.196

38. WONG, J.F. Factors affecting open building implementation in high density mass housing design in Hong Kong. Habitat International, v. 34, n. 2, p. 174-182, 2010. doi: http://dx.doi.org/10.1016/j.habitatint.2009.09.001

39. NA, L.T.H.; PARK, J.H.; et al. Lessons from vietnamese urban street houses for contemporary high-rise housing. Open House International, v. 38, n. 2, p. 31-46, 2013.

40. DURTH, Werner; MAY, R. Selected German Projects. Architectural Design, v. 77, n. 5, p. 50-59, 2007. doi: http://dx.doi.org/10.1002/ad.515

41. PENAFIEL, José Domingo. Edificio Costanera: Puerto Montt, Chile. ARQ (SANTIAGO), SANTIAGO , n. 66, p. 36-41, agosto 2007 . HTTP:/DX.DOI.ORG/10.4067/S0717-69962007000200006..

42. FERNANDEZ EYZAGUIRRE, Cristián. EDIFICIO SANTA MARÍA: SANTIAGO, CHILE. ARQ (SANTIAGO), SANTIAGO , n. 66, p. 42-49, agosto 2007 . doi: http://dx.doi.org/10.4067/s0717-69962007000200007.

43. GARCIA, Cristóbal. Espacios de innovación y transformación: el caso de IDEO. ARQ (SANTIAGO), Santiago , n. 66, p. 54-59, agosto 2007 . http://dx.doi.org/10.4067/s0717-69962007000200009..

44. TOMITA, H.; ISHII, M. The Influence of Hannes Meyer and the Bauhaus Brigade on 1930s Soviet Architecture. Journal of Asian Architecture and Building Engineering, v. 13, n. 1, p. 49-56, 2014. doi: https://doi.org/10.3130/jaabe.13.49

45. FROHN, Marc; ROJAS, Mario. Goethe Institut Temporal, Providencia, Chile: FAR FROHN \& ROJAS, 2010 - 2011. ARQ (SANTIAGO), Santiago , n. 78, p. 16-19, agosto 2011. http://dx.doi.org/10.4067/s0717-69962011000200003.

46. ZUBIR, S.S.; NORHISHAM, Q.; et al. Sustainable space optimization and function versatility through mass displacement WIT Transactions on Ecology and the Environment, v. 186, p. 375-386, 2014. doi: http://dx.doi.org/ $10.2495 /$ ESUS140321

47. LIN, P.C.; CHEN, K.N.; et al. Before there was a place called library - Library space as an invisible factor affecting students' learning. Libri, v. 60, n. 4, p. 339-351, 2010. doi: http://dx.doi.org/ 10.1515/libr.2010.029

48. TAN, G. The Open and Adaptive Tradition: Applying the Concepts of Open Building and Multi-Purpose Design in Traditional Chinese Vernacular Architecture. Journal of Asian Architecture and Building Engineering, v. 10, n. 1, p. 7-14, 2011. doi: http://dx.doi.org/10.3130/jaabe.10.7

49. SUNG-HWA, K.; BEISI, J. Flexible building and construction systems in traditional Korean architecture. Open House International, v. 37, n. 3, p. 16-27, 2012.

50. BRINKHUIJSEN, M.; STEENHUIS, M. Park design between community and professionals: the Wollefoppenpark in Rotterdam. Journal of Landscape Architecture, v. 10, n. 3, p. 28-37, 2015. doi: https://doi.org/10.1080/18626033.2015.1094902 
51. NIJS, J.C.; DURMISEVIC, E.; et al. Interface design for open systems building. Open House International, v. 36, n. 1, p. $35-43,2011$.

52. GERAEDTS, R. Success and Failure in flexible building. Open House International, v. 36, n. 1, p. 54-62, 2011.

53. BARROS, R. R. M. P.; PINA, S. A. M. G. Sinfonia inacabada da habitação coletiva: lições a partir do PREVI para uma arquitetura de possibilidades. Ambiente Construído, Porto Alegre, v. 12, n. 3, p. 7-26, 2012. doi: http://dx.doi.org/10.1590/S1678-86212012000300002

54. BRANDÃO, D. Q. Disposições técnicas e diretrizes para projeto de habitações sociais evolutivas. Ambiente Construído, Porto Alegre, v. 11, n. 2, p. 73-96, 2011. doi: http://dx.doi.org/10.1590/S1678-86212011000200006

\section{${ }^{1}$ Heliara Aparecida Costa}

Arquiteta e Urbanista. Doutoranda em Arquitetura e Urbanismo. Endereço postal: IAU - Instituto de Arquitetura e Urbanismo. Avenida Trabalhador São-Carlense, 400 - Parque Arnold Schimidt - São Carlos, SP, Brasil, 13566-590.

\section{Louise Logsdon}

Arquiteta e Urbanista. Doutoranda em Arquitetura e Urbanismo. Endereço postal: IAU - Instituto de Arquitetura e Urbanismo. Avenida Trabalhador São-Carlense, 400 - Parque Arnold Schimidt - São Carlos, SP, Brasil, 13566-590.

\section{${ }^{3}$ Márcio Minto Fabricio}

Engenheiro Civil. Doutor em Engenharia. Endereço postal: IAU - Instituto de Arquitetura e Urbanismo. Avenida Trabalhador SãoCarlense, 400 - Parque Arnold Schimidt - São Carlos, SP, Brasil, 13566-590. 